\title{
Defining function in Neolithic ceramics: the example of Makriyalos, Greece
}

\author{
Dushka Urem-Kotsou*, Kostas Kotsakis* and Ben Stern** \\ * Department of Archaeology, Aristotle University, Thessaloniki, Greece \\ durem@ hist.auth.gr \& kotsakis@ hist.auth.gr \\ **Department of Archaeological Sciences, University of Bradford, UK \\ b.stern@Bradford.ac.uk
}

\begin{abstract}
Recent development in chemical analyses of organic remains in archaeological ceramics gives new possibilities to the study of pottery use. They could be of crucial importance in assessing vessel's use, especially when combined with contextual, technomorphological and use-alteration analysis data. Using the example of the late Neolithic pottery from Makriyalos, Northern Greece, we discuss some of the problems in determining the use of the vessels from archaeological context, and show the benefits of integrating chemical analysis of organic remains in approaching this issue.

IZVLEČEK - Sodobni razvoj kemičnih analiz organskih ostankov v arheološki keramiki odpira nove možnosti raziskav njene uporabe. Te analize bi lahko bile ključnega pomena pri ocenjevanju uporabe posodja, še posebej v kombinaciji z drugimi kontekstualnimi ter tehnološko-morfološkimi podatki in podatki o spremembi namembnosti. Za primer smo vzeli poznoneolitsko keramiko z najdišč Makriyalos v severni Grčiji. Razpravljamo o nekaterih težavah pri določevanju uporabe posod na podlagi arheološkega konteksta in pokažemo prednosti, če upoštevamo kemične analize organskih ostankov.
\end{abstract}

KEY WORDS - pottery function; residue analyses; lipids; GC-MS; late Neolithic; Makriyalos; Northern Greece

\section{INTRODUCTION}

The relation between pottery and the introduction of the Neolithic way of life has always been considered a very close one. Traditionally, pottery has been connected to sedentism, storage and large-scale food production, which are regarded as the broad results of the introduction of farming. Pottery in this sense was viewed as an integral part of an intensification process established in the relation between humans and nature (Arnold 1985). The functionalist aspect of this approach has rightly been questioned by recent archaeological thought and as a result of this critique more emphasis is now laid on the independence of the ceramic phenomenon. Pottery in this sense should not be viewed as a subordinate part of the "Neolithic package", serving the needs of the "Neolithic", but as a potentially important aspect of the material culture invested with a multiplicity of meanings grounded on practical use. It is very meaningful, in this respect, that although in some cases pottery fol- lows the introduction of agriculture (though not directly connected with it, as in the case of the Near Eastern Aceramic), in others, pottery clearly predates this distinct shift in production means and relations (Zhang Chi 1999; Ikawa-Smith 1976; Kotsakis 2001).

Pottery, therefore, is, one way or another, closely related to everyday practices. It seems, however, that in some parts of the world the emergence of first pottery was not connected with such activities. During the last decade some scholars (Vitelli 1989; Perlès 2001; Björk 1995) have questioned the prevailing opinion which relates the beginning of production of pottery with the everyday needs in preparation and storing of food. It has been observed that the use and the role of the first pottery worldwide were not the same. Even in a relatively limited geographical area such as Mediterranean region and the 
Balkans considerable differences exist. Thus, while in Southern Italy, France, Northern Balkans and Bulgaria first vessels had more utilitarian character (Perlès 1992.153; Plucienik 1997; Perlès 2001. 217-218), it seems that in Greece, to the contrary, the first pottery was not produced for cooking and storing (Vitelli 1989; 1993; 1999; Björk 1995). It is suggested that the early Neolithic Greek vessels were used merely for consumption and display. Furthermore, vessels role, their meaning and their practical use throughout the Neolithic gradually changed. Thus, concerning Greek Neolithic it has been proposed that early and middle Neolithic vessels were not utilitarian and only in the late Neolithic they became widely used in everyday life for cooking, storing, serving and the consumption of food. In particular, in the early Greek Neolithic period no vessel was recognized as cooking pot, while in the late Neolithic approximately $30 \%$ of the pots were used for cooking. The absence of cooking pots in the early Neolithic and their appearance almost 1000 years after the emergence of the first pottery in Greece, indicate the differences in diet and food habits between the early and the late Neolithic in Greece. The beginning of the use of pottery for cooking suggests the introduction of new forms of food preparation and changes in food habits. This change probably involves the introduction of new kinds of food as well (Hansen 2000).

Preparation and the consumption of food and drink are closely related to all aspects of social, economic and political life. The study of food and food habits, as a form of cultural expression, could provide evidence about the whole field of social relations. Pots as an integral part of the practices related to eating and drinking embody particular cultural perceptions which society has on food. The complexity and combination of a ceramic assemblage will almost certainly reflect or represent a particular set of social relations. These make the pottery, food and the activities related to its preparation and consumption powerful means for study and understanding the structure of any given society. Moreover, they are of particular importance for the study of Neolithic societies, as the information about the palaeodiet and food habits in this period is mainly restricted to archaeozoological and often scarce archaeobotanical remains. The absence of figurative representations and written sources, which appear in Greece from the Bronze Age onward, make the Neolithic pottery basic source of information concerning food habits, social relationships and social identity of the members of certain society.

\section{POTTERY FUNCTION}

To approach the aforementioned issues through the study of pottery it is necessary to understand their practical use. Weather vessels are viewed as exchange or symbolic objects, non-utilitarian or utilitarian artefacts the majority of them were produced for certain purposes. Their morphological, technological and stylistic characteristics are correlated to the practical task for which they were manufactured, and are closely related to the social context of their makers and their users. Elements such as fabric, morphology, decoration and surface treatment all structure the way the pot is socially perceived, and will determine how it is used in specific social contexts. At the same time these elements determine the suitability of the pots for certain practical use.

It is obvious from the above that the issue of pottery use is of crucial importance for understanding the structure and the complexity of past human societies. It is also important for understanding technological, morphological and stylistic variability of pottery assemblage since both the practical and the social aspect of vessels are inseparable part of their identity.

Although it is one of the basic aspects of pottery, archaeologists have given relatively little consideration to the question of vessels use. Research concerning vessel function has been developed especially during the 80's where the focus was on the morphological and technological, mainly physical and mechanical characteristics of the pots, as well as on the use alteration of vessel's surfaces. In the last decade the efforts have been put on the recognition of the actual food cooked, consumed and stored in the vessels by applying various methods of chemical analysis of organic remains.

Identification of vessel function has been approached so far by analysing:

- morphological characteristics (including shape and size);

- use alteration of vessel surfaces (soot deposition, charred organic remains, oxidation discoloration, interior surface pitting);

- physical and mechanical properties of the vessels (including paste and temper composition, thermal shock resistance, mechanical strength);

- studies of preserved contents;

- chemical analysis of organic residues;

- pollen analysis;

- archaeological context in which vessels are found. 
The study of vessels function is based on the believe that pots are tools and are made to be used for certain purposes. They should have appropriate physical and mechanical properties to fit certain activity. The subject is approached by studying observable and measurable properties such as vessel shape and size (Smith 1988; Hally 1986; Henrickson and McDonald 1983), fabric including paste composition (Braun 1983; Steponaitis 1984; Bronitsky 1986), surface treatment (Shiffer 1988b; 1990), and use-alteration analysis (Hally 1983; Skibo 1992; Kobayashi 1994). Using materials science analytical techniques the study focus on behaviorally relevant performance characteristics including impact and thermal shock resistance (Bronitsky 1986; Brinitsky and Hammer 1986; Mabry et al. 1988), abrasion resistance (Shiffer and Skibo 1989), and heating and evaporative cooling effectiveness (Schiffer 1988; 1990; 1994). Mach of the effort was put on seeking the attributes - predictors of use - that would have universal value and cross cultural applicability. The research on pottery function could be broadly divided on the study of intended vessel function and the study of actual vessel function (Rice 1987.207-242; Skibo 1992.35). The former aiming at reconstructing what a vessel was manufactured for, and the latter how the vessel was in fact used.

Recent development in analytical chemistry and biochemistry has opened up new possibilities in the study of pottery use. A growing number of studies, most of them focusing on the analysis of lipids, show the potential of chemical analysis of visible and absorbed organic residues in approaching the issues of palaeodiet and the actual use of vessels of archaeological origin. Among various techniques applied so far, a range of chromatographic techniques is preferred, with notable success of gas chromatography and gas chromatography-mass spectrometry (Heron $\mathcal{E}$ Evershed 1993 for review). Based on the ability to resolve the individual components of the often complex mixture of lipids found in potsherds, these techniques have been successively used in the identification of natural products such as resins, tars, pitch and beeswax (Aveling \& Heron 1999; Hayek et al. 1990; Heron et al. 1994; Regert et al. 1998; Evershed et al. 1997). Also, to identify the components of foodstuff processed or stored in ancient vessels (Stern et al. 2000; Evershed et al. 1991; Evershed et al. 1997).

Most of the studies concerning pottery function draw on only a few of the parameters mentioned above, which were not always applied to the whole pottery assemblage. Moreover, many of these parameters have been developed within the frame of ethnographical research where whole vessels were studied. As expected, there could be difficulties in applying methods developed from the study of whole pots to approach the use of pottery assemblage from archaeological context, usually comprised of thousands and thousands of fragments that seldom complete whole pots. What could be easily perceivable on the whole pots, especially those still in use, as it is in ethnographical context, could be difficult to recognize or measure on the fragments, often scaly and abraded, scattered around and out of their context of use.

The study of pottery function becomes even more complex by the fact that vessels could have multiple uses, or could be reused after being considered not proper for their primary function (Skibo 1992.38; Deal 1998.107-111; Rice 1987).

Using the example of the late Neolithic pottery from Makriyalos, Northern Greece, we discuss some of the problems in determining the use of the vessels from archaeological context, and show the benefits of integrating chemical analysis of organic remains in approaching this issue.

\section{MAKRIYALOS SITE}

The Neolithic settlement at Makriyalos is situated in the coastal area of Pieria, Northern Greece, less than $2 \mathrm{~km}$ from the sea (Fig. 1). Fifteen $\mathrm{km}$ to the west lie the Pieria Mountains. The settlement is located on the gentle slopes of a natural low hill. The prehistoric settlement covers about 50 ha and is one of the largest non-tell sites in prehistoric Macedonia. Two main phases of occupation, Makriyalos I and II, both dated to the Late Neolithic period, are clearly distinguished (Pappa and Besios 1999).

\section{The pottery}

The results we discuss here regard the study of pottery use that belongs to the earlier settlement phase dated to the second half of the $6^{\text {th }}$ millennium, namely to the period between 5400-4900 BC. Pottery study is still in progress although some parts of it have already been accomplished. The study of pottery use is a part of a detailed contextual study of vessels' use life that includes production, use and deposition of the pots throughout the whole settlement. To this end a series of analytical techniques is 
employed, as well as a traditional examination of the pottery. These involve analysis of technological, morphological and stylistic characteristics of the vessels, use-alteration and residue analysis. It should be mentioned that Makriyalos earlier phase gave enormous amount of pottery sherds. Although approximate numbers of pots haven't been calculated yet, there are certainly a great number of vessels. For illustration, more then 200 cups have been recorded so far. Despite the great amount of pottery sherds there is limited number of vessels for witch the whole profile could be reconstructed. No whole vessel is found.

On the base of shape, size and use-wear characteristics 4 broad functional classes are defined: table ware (Fig. 2: 1-3), vessels suitable for serving/storage/ transferring of liquids (Fig. 2: 4-6), cooking pots (Fig. 3: 1), and long term storage vessels (Fig. 3: 3). Considerable number of vessels couldn't be assigned to any concrete use.

Within each broad functional group notable morphological variability is observed, although not to the same extent in each group. As expected, the variability increases when technological and stylistic characteristics were considered together with morphological. It is beyond the scope of this study to discuss these results in detail. However, it should be mentioned that some of the subgroups are remarkably standardized in terms of shape, size, fabric and decoration such as bowls and to lesser extend long term storage vessels. Somewhat greater variability shows the vessels for Serving/Storage/Transferring liquids and extreme variability small vessels - i.e. cups.

Concerning cooking pots limited variability has been observed. The majority belong to coarse shelltempered fabric. Medium to fine quartz-tempered cooking pots were also recognised, although they comprise a minor group. It should be noted that in shell-tempered ware several different shapes has been recorded such as large shallow basins, conical and hemyspherical bowls and spherical pots with restricted rim and the upper part. Medium/fine quartztempered cooking pots were recognized only by charred organic remains deposited on the bottom of their oxidized bases. There is no indication about the shape of these pots. The variability in fabric, to certain extend, has been ascribed to the context of their production. However, it could also be related to cooking techniques, since the medium/fine quartztempered pots seem to be less porous then their

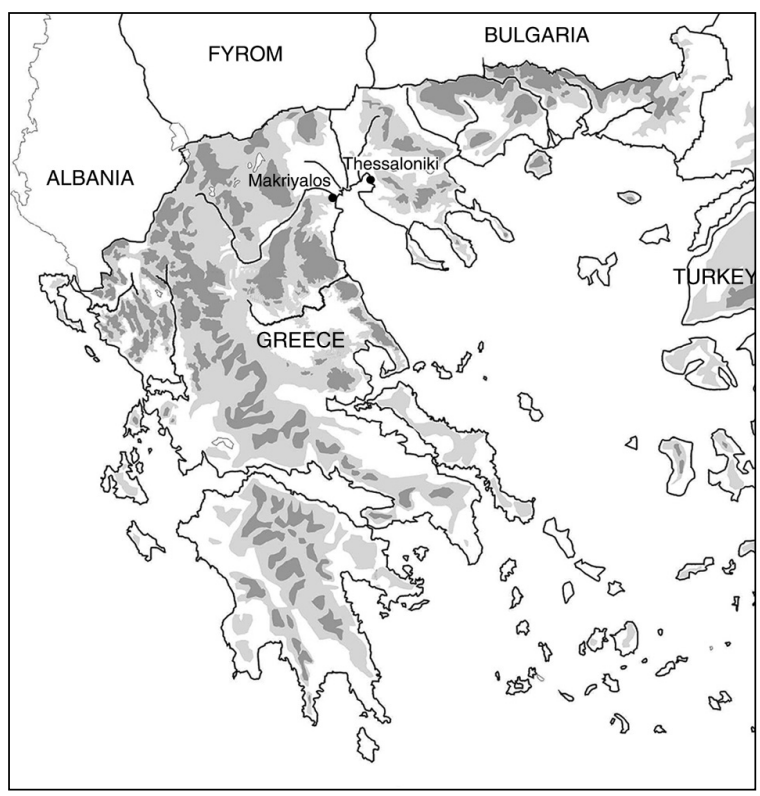

Fig. 1. Location of Makriyalos site.

course shell-tempered counterparts. Thus, it seems reasonable to suppose that low porous cooking pots were used for boiled food and the other for cooking of less liquid food.

It should be mentioned that in the case of Makriyalos pottery assemblage, comprised mainly from fragments, sooting clouds, which is proposed as one of the basic means for recognizing cooking pots, were not always of much help since they could be mixed up with uneven colouring formed during the last phase of manufacturing process - firing of the pot itself. This is not surprising, since Makriyalos pots are fired in open fire that often result in pottery with uneven coloured surfaces. Uneven colouring has been found on many vessels that were not used for cooking, such as table ware including cups and bowls, as well as storage vessels (Fig. 4). Very often they do not differ from that on cooking pots.

Oxidation discoloration, also proposed as one of the basic means in recognition of pots used over fire, could be misleading as well, as the case with the bases of medium/fine quartz-tempered cooking pots show. These oxidized bases are, in terms of their fabric, surface treatment and colour, similar to jags for short-term storage of liquids and their sherds could be easily mixed up, since the jugs were fired in oxidized atmosphere, which gave them reddish colour often similar to this of cooking pots bases. Only burnt organic remains deposited onto the bottom of the bases indicate their use over fire. It is observed that the Makriyalos cooking pots have oxidized bases and soot deposition on the middle and the up- 
per part of the outer side of their body, which indicate that they were placed in the fire thus being in a direct contact with fuel. The presence of charred organic remains on the bottoms of cooking pots is not rare.

The study of pottery distribution, although still in progress, gives interesting evidence about the practices concerning preparation and the consumption of food. It is observed that distribution of different cooking pot types is not homogeneous throughout the settlement, nor it is in relation to the dwellings and their environment. This suggests that different cooking practices, like baking, boiling and stewing, were not done at the same place. According to the distribution of cooking vessels, baking took place most probably outdoors and is not connected to each pit, while boiling and stewing seems to be more indoors practices and linked to individual pits.

The results of technomorphological and use-alteration analysis and the evidence of the pottery distribution stress the needs for better understanding of the actual pottery use, especially of those used for cooking.

\section{Chemical analysis of organic remains}

In order to understand how observed technomorphological and stylistic variability is correlated to the

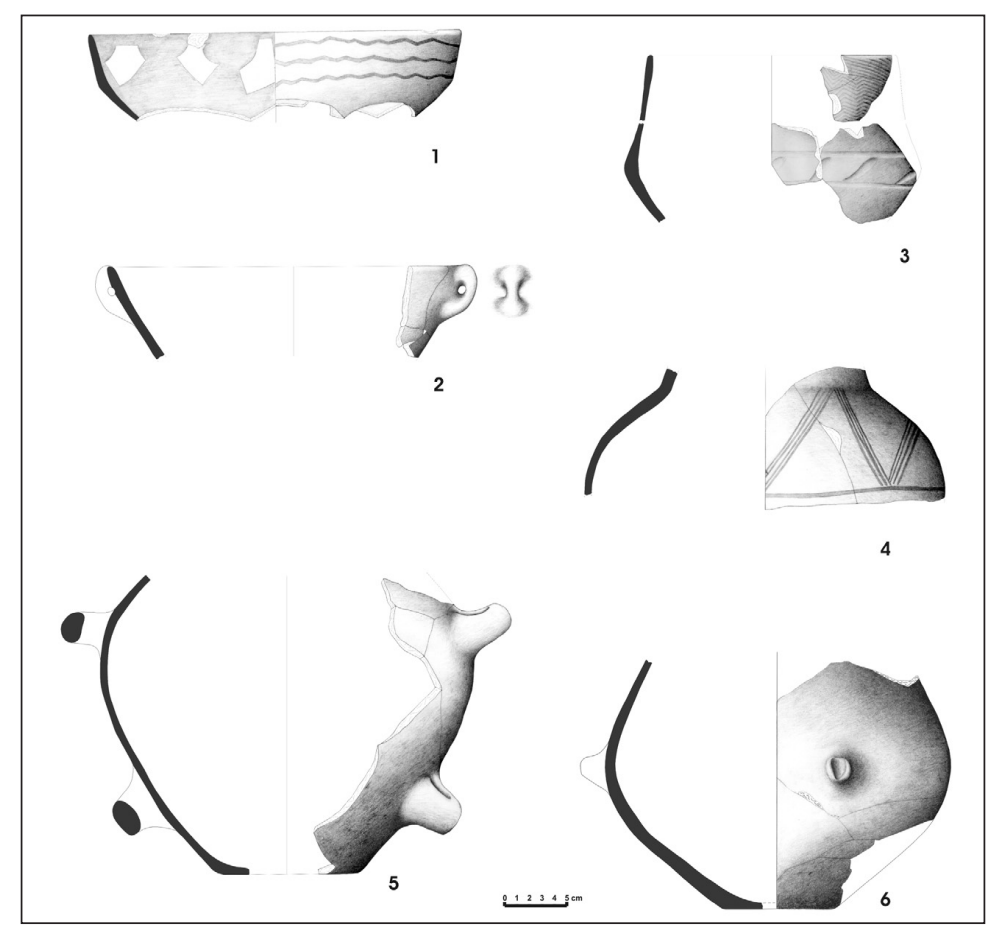

Fig. 2. Main shapes of table ware (1-3), closed shape amphorae (4-6). actual use and to the food cooked, consumed and stored in the pots, chemical analysis of organic remains was planed. To this end a pilot study, results of which we represent in part here, was carried out in the Department of Archaeological Sciences at the University of Bradford, UK. The aim of the study was twofold. Since the Makriyalos vessels are more then 7000 years old, our main consideration was, on the one hand the level of surviving of organic residues, and on the other the possibilities to reassess the use of the pots indicated by technomorphological, stylistic and use-alteration analysis. To this end sherds of 19 pots that represent a range of categories of vessel shape, size and fabric were selected. They belong to the main use categories, although the emphasis was put on cooking pots. Three sherds from the vessels, which couldn't be assigned to any concrete use, were also included.

In an effort to avoid the effects that could have different burial environments on the preservation of organic residues, all samples were taken from similar environments, namely from two pits. The majority of samples come from one pit and only two belong to the other. Some sherds had visible remains and some had no indication of any organic residue. All pottery was subjected to the ordinary post-excavation treatment including washing with tap water and storing in plastic bags. One of the factors that could affect the results of chemical analysis is contamination from burial environment, post-excavation and laboratory handling of pottery. In order to control the contamination issue, sampling procedure involved the removal of potential contamination by scraping the surfaces, followed by samples taken to a 1-2 $\mathrm{mm}$ depth from the interior of the inner end the outer side of the vessel's wall. Samples from the surface layer and the sherd interior were treated separately. The samples were analysed by gas chromatography (GC) and gas chromatography-mass spectrometry (GC-MS) analytical techniques. The procedure applied to all but one sample is the same as described in Urem-Kotsou et al. (in press).

\section{Results}

\section{Use assessment analysis}

Three vessels types were chosen for use assessment analysis, these are each 
represented by two sherds. Two fragmented base sherds represent the 4-handled jugs (Fig. 5). Two fragmented bases represent medium/fine quartz tempered cooking pots of unknown shape. Both vessel types are similar in terms of their fabric, surface treatment and colour. This makes distinguishing the vessel types difficult without diagnostic morphological features. Two large sherds (upper part of the vessels including rim) represent the large conical bowls (Fig. 3: 2) similar to the medium/fine quartz tempered cooking pots in terms of their fabric.

Technomorphological and use-alteration analysis of 4-handled jags gave controversial indications about their actual use. They are of closed shape, low-porosity and fired in oxidized atmosphere which was not always well controlled judging from uneven colour of their surface (Fig. 5). Their morphological and technological characteristics indicate serving/ storing/transferring of liquids. However, soot depositions on the bases of some of similar vessel types indicate a possible reuse as cooking pots. This hypo-

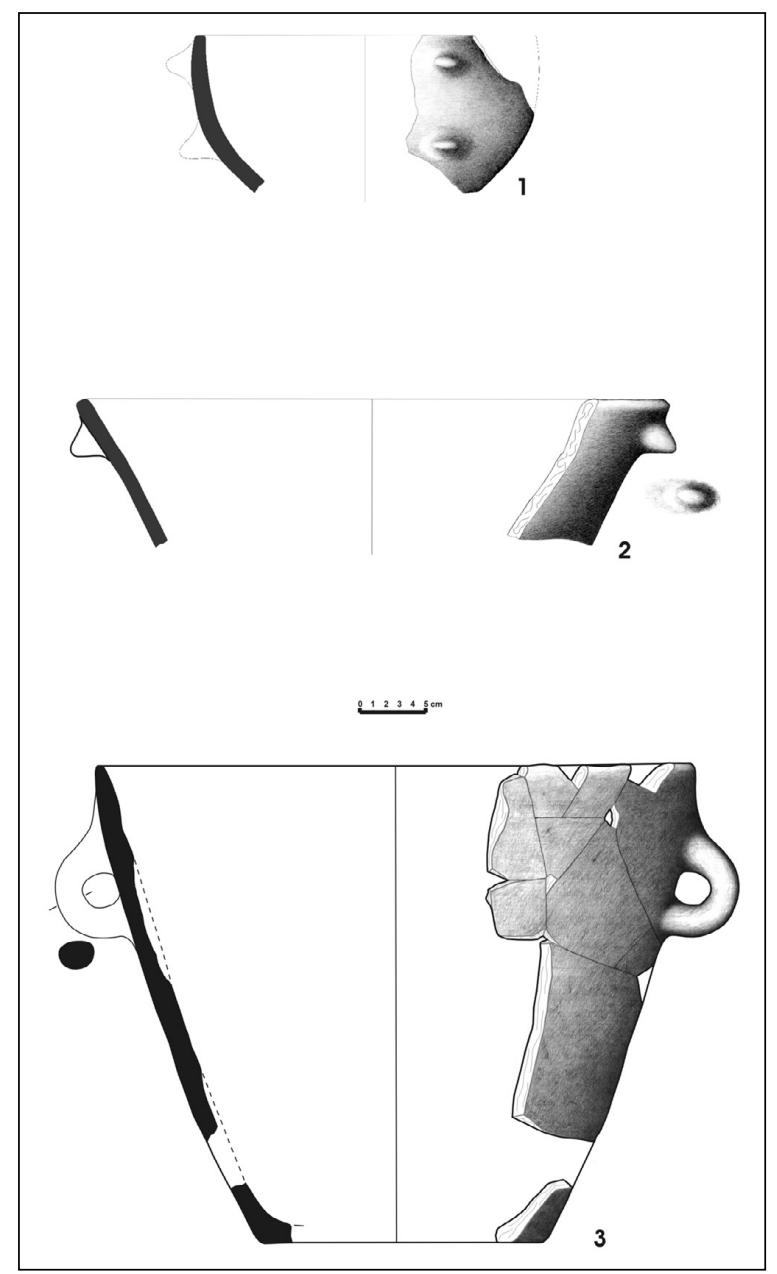

Fig. 3. Main shapes of: 1 cooking pot, 2 unknown use, 3 storage vessel. thesis was supported by the traces of black organic remains deposited onto the bottom and the lower part of several other jugs of the same type, which initially looked similar to burnt food remains.

Two fragmented bases of 4-handled jugs selected for analysis had scanty traces of black remains, deposited onto the bottom and the lower part of the inner vessels walls, which looked as burnt food residues that indicate their use over fire.

In order to examine the relation between 4-handled jugs and medium/fine quartz-tempered cooking pots, two fragmented bases of the latter were selected. Macroscopically both were similar to the bases of 4handled jugs, oxidized and with black organic remains on their bottoms.

Of possible interest to the issue of medium/fine quartz-tempered cooking pots is the case of two large conical bowls (Fig. 3: 2). Both, on the base of technomorphological and use-alteration analysis, couldn't be assigned to any concrete use. Both bowls are of medium to fine quartz-tempered fabric and low porosity. Their surfaces are smoothed and of greyish uneven colour. Both belong to the same vessel type and are of similar size judging from their rim diameter (35 and 37 respectively), wall angle and wall thickness. No visible traces of organic remains were observed.

\section{Organic residue analysis}

The results of chemical analysis by GC-MS show that black organic remains from the bottom of the 4-handled jugs are not burned food residues but remains of birch bark tar (Urem-Kotsou et al. in press). This highlights the importance of chemical analysis in the identification of amorphous visible residues. These residues were found only on the interior surface, suggesting that the birch bark tar was used for lining the interior walls of the vessels, possibly to reduce the permeability. The intention to reduce the permeability of the pots, especially those of close shape, indicates that vessels contained liquids.

Chemical analysis of visible organic remains from the bottom of two medium/fine quartz tempered cooking pots bases didn't show any traces of birch bark tar.

Chemical analysis of two large bowls revealed the presence of free fatty acids, such as palmitic $\left(\mathrm{C}_{16: 0}\right)$ and stearic $\left(\mathrm{C}_{18: 0}\right)$ acids. Traces of ketones were also detected in both vessels. Unfortunately, it is not pos- 


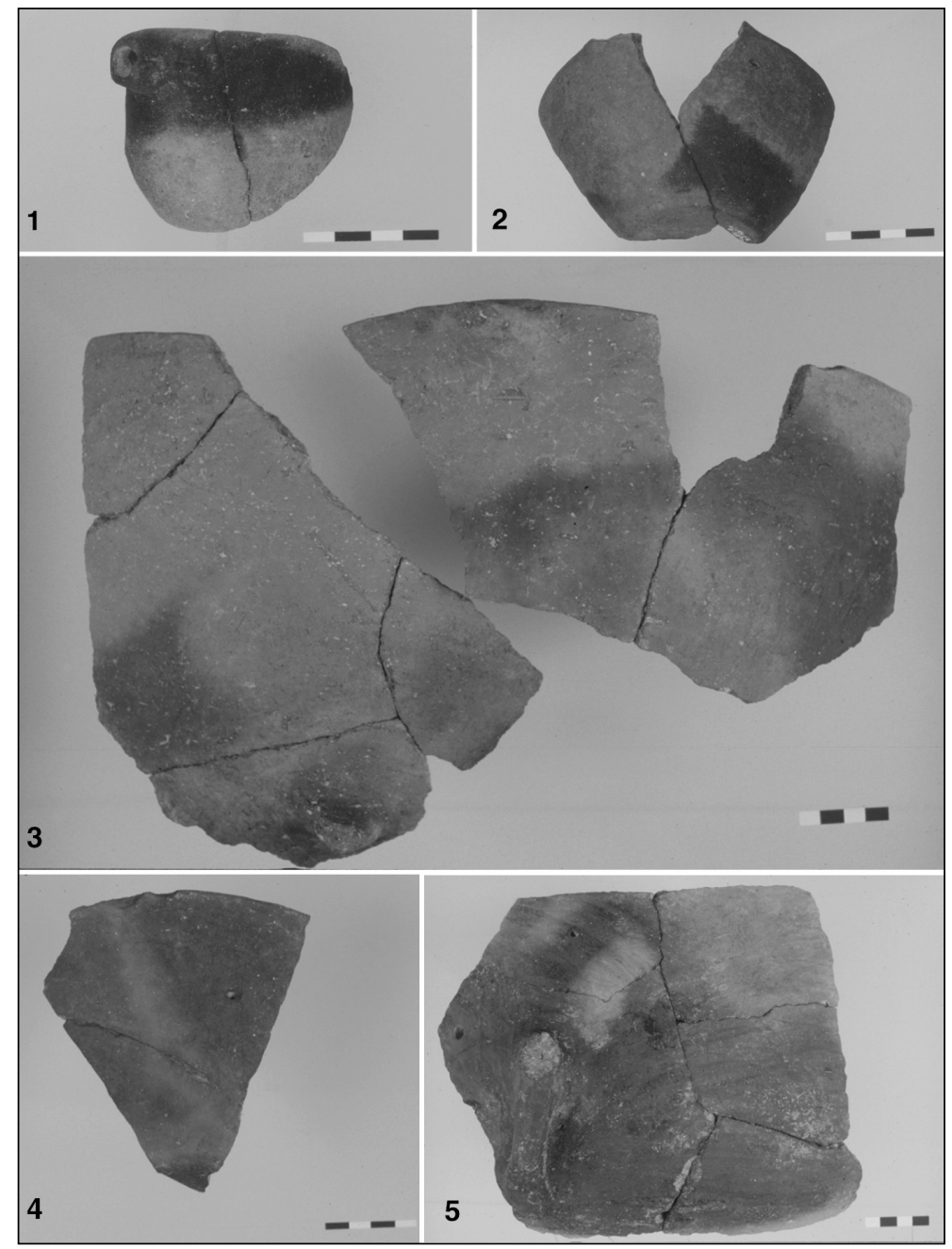

Fig. 4. Vessels of different use-types with sooting clouds: 1-2 cups, 3 cooking pot, 4 table ware, 5 storage vessel.

sible to further identify the ketones. However, by comparison to previously published work, were retention time and the range of proportion of ketones are published, the ketones found in both Makriyalos pots could be K31, K33 and K35 (Evershed et al. 1995; Raven et al. 1997). In this work is pointed out that K31, K33 and K35 are formed by pyrolysis of acyl lipids, although ketones absorbed in vessel's matrix could also derive from cooking of food of plant origin (Charters et al. 1997). Concerning two Makriyalos large bowls, ketones were detected in all but one sample. In particular, they were identify in the samples taken from the interior of the sherds of both vessels, in the same range proportion and retention time as published above. In the surface layer sample of one large bowl ketones are not recorded. This sample yields negligible amounts of lipids and differs from the composition of the subsequent sample taken from the sherd's interior. This suggests that ketones in this vessel are not a result of soil contamination, but originate from the vessel's con- tent. However, although their presence in the interior and exterior of sherds from both vessels suggests they could have migrated through the vessel by the successive use in processing food, contamination from the soil cannot be excluded.

At the present state of research, consequently, chemical analyses cannot fully support the use of large bowls for cooking, since there is no carbon numbers to identify the ketones. They, nevertheless, give an interesting direction to the study of Makriyalos pottery, indicating a possible group of vessels to which fine quartz-tempered pots bases belong.

\section{DISCUSSION}

As already noted, there are a number of parameters proposed for the study of pottery use. Many of them have been developed in ethnographical research. As we found out in the study of Makriyalos pottery, there are difficulties in applying proposed methods to archaeological ceramics. Thus, some basic parameters to assess pottery use, such as soot deposits and interior surface pitting, were not of much help in our study since pottery is remarkably fragmented, abraded and sometimes scaly. Even visible organic remains could be misleading, as the example of 4-handled jugs coated with birch bark tar show. What looks very much as burnt food residues could very well be something completely different.

Considerable effort has been put during the last two decades in the study of cooking pots technology, in order to find relevant attributes, which would help the recognition of cooking vessels. Besides the usealteration characteristics, one of the basic attributes proposed for recognition of cooking pots is their fabric, and in particular, the type, size and the quantity of non-plastic inclusions in ceramic matrix. Thus, as predictor-of-use characteristics for recognition of cooking pots, coarse fabric is proposed with shelltemper as most suitable, although sandy-tempered and quartz-tempered cooking pots are also reported. While the growing number of studies concerning clay 

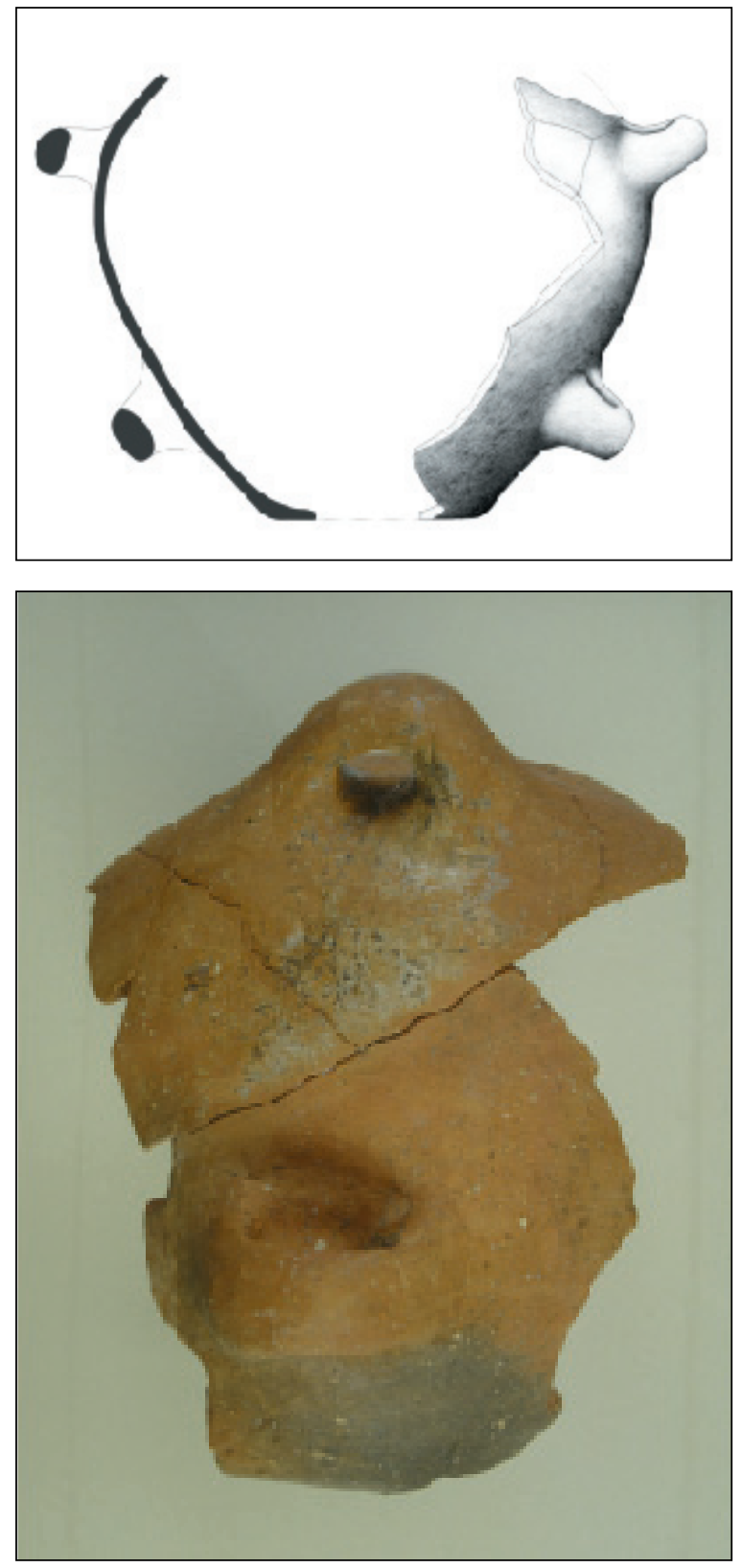

Fig. 5. Closed shape vessel with sooting clouds on its base.

non-plastic inclusions show that type of inclusions is not that important, the coarseness of the pot fabric is stressed as a crucial factor.

However, Makriyalos medium/fine quartz-tempered cooking pots show that coarseness should not be taken for granted. Even when, in a ceramic assemblage, cooking pots of typical fabric composition exist, different cooking ware technologies could equally be present. This is the case of Makriyalos, where apart from coarse shell-tempered pots, medium and fine fabrics could also be connected to cooking activities. In a situation like this, predictor-of-use characteristics are potentially misleading.
It has already been observed by some scholars that proposed relationship between various parameters, such as relationship between form, fabric and function, could be ambiguous and that cultural dimension of technical behaviours shouldn't be ignored (Woods 1986; Gosselain 1998). Makriyalos medium/ fine cooking pots show that fine fabric could also be used for manufacturing cooking pots. Thus in the same assemblage the whole range of fabrics in cooking pots could be found. This can be linked to the context of their production but could also be linked to the cooking techniques. Not to mention that these variability could be related to the kind of food as well. Chemical analysis of organic remains could substantially contribute to this issue.

Although not easy to be traced, the understanding of actual vessels use directly affect our understanding of the activities concerning food preparation and consumption, and their relation to the use of space, among others. As could be seen on Makriyalos example, contextual study of pottery use indicate that baking was most probably a matter of group of households and took place outdoors, which indicate sharing between people. Boiling and stewing were more matter of individual household, since boiling and stewing pots were found in individual pits. These are important information for understanding the food habits of past human societies. In conclusion, we could stress the importance of combined ceramic and chemical analysis for understanding everyday activities in past societies through pottery use.

\section{ACKNOWLEDGEMENTS}

K. Kotsakis and D. Urem-Kotsou would like to thank the Institute for the Aegean Prehistory for financial support of Makriyalos pottery study and Mrs. M. Pappa for making the material available. D. UremKotsou is greatly indebted to Dr. Carl Heron for help and support in chemical analysis, which took place in Bradford with financial assistance of the British School at Athens. We thank A. Vargas and S. Savvidou for help with the figures. 


\section{REFERENCES}

ARNOLD D. E. 1985. Ceramic Theory and Cultural Process. Cambridge, Cambridge University Press.

AVELING E. M. and HERON C. 1999. Chewing tar in the early Holocene: An archaeological and ethnographic evaluation. Antiquity 73: 579-584.

BJÖRK C. 1995. Early Pottery in Greece: A Technological and Functional Analysis of the Evidence from Neoliothic Achilleon Thessaly. Studies in Mediterranean Archaeology. Paul Åströms Förlag, Sweden.

BRAUN D. P. 1983. Pots as Tools. In J. A. Moore and A. S. Keene (eds.), Archaeological Hammers and Theories: 107-134.

BRONITSKY G. 1986. The Use of Material Science Techniques in the Study of Pottery Construction and Use. In M. Schiffer (ed.), Advances in Archaeological Method and Theory, Vol. 9: 209-276.

BRONITSKY G. and HAMER R.1986. Experiments in Ceramic Technology: The Effects of Various Tempering Materials on Impact and Thermal-Shock Resistance. American Antiquity 51 (1): 89-101.

CHARTERS S., EVERSHED R. P., BLINKHORN P. and QUYE A. 1997. Simulation experiments for determining the use of ancient pottery vessels: The behaviour of epicuticular leaf wax during boiling of a leafy vegetable. Journal of Archaeological Science 24: $1-7$.

DEAL M. 1998. Pottery Ethnoarchaeology in the Central Maya Highlands. University of Utah Press, Salt Lake City.

EVERSHED R. P., STOTT A. W. 1995. Formation of long-chain ketones in ancient pottery vessels by pyrolysis of acyl lipids. Tetrahedron Letters 36 (48): 8875-8878.

EVERSHED R. P., MOTTRAM H. R., DUDD S. N., CHARTER S., STOTT A. W., GIBSON A. M., CONNER A., BLINKHORN P. W. and REEVES V.1997. New criteria for the identification of animal fats preserved in archaeological pottery. Naturwissenschaften 84: 402406.

EVERSHED R. P., VAUGHAN S. J., DUDD S. N. and SOLES J. S. 1997. Beeswax in lamps and conical cups from Late Minoan Crete. Antiquity 71: 979-985.
GOSSELAIN 0. 1998. Social and Technical Identity in a Clay Crystal Ball. In M. T. Stark (ed.), The Archaeology of Social Boundaries: 78-106.

HALLY D. J. 1983. Use Alteration of Pottery Vessel Surface: An Important Source of Evidence for the Identification of Vessel Function. North American Archaeologist 4 (1): 3-26.

1986. The Identification of Vessel Function: A Case of Nortwest georgia. American Antiquity 51 (2): 267-295.

HANSEN J. 2000. Palaeoethnobotany and Palaeodiet in the Aegean Region: Notes on Legumes Toxicity and Related Pathologies. In S. J. Vaughan and W. D. E. Coulson (eds.): Palaeodiet in the Aegean. Wiener Laboratory Monograph 1: 13-28.

HAYEK E., KRENMAYR P. and LOHNINGER H.1990. Identification of archaeological and recent wood tar pitches using gas chromatography/mass spectrometry and pattern recognition. Analytical Chemistry 62: 2038-2043.

HENRICKSON E., McDONALD M. 1983. Ceramic Form and Function: An Ethnographic Search and an Archaeological Application. American Anthropologist 85: 630-643.

HERON C. and EVERSHED R. P. 1993. The analysis of organic residues and the study of pottery use. In M. Shiffer (ed.), Archaeological Method and Theory: 247-284.

HERON C., NEMCEK N., BONFIELD K. M., DIXON D. and OTTAWAY B. S. 1994. The chemistry of Neolithic Beeswax. Naturwissenschaften 81: 266-269.

IKAWA-SMITH F. 1976. On Ceramic Technology in East Asia. Current Anthropology 17: 513-515.

KOBAYASHI M. 1994. Use-Alteration Analysis of Kalinga Pottery: Interior Carbon Deposits of Cooking Pots. In W. Longacre and J. Skibo (eds.), Kalinga Ethnoarchaeology: Expanding Archaeological Method and Theory: 127-168.

KOTSAKIS K. 2001. Mesolithic to Neolithic in Greece. Continuity, discontinuity or change of course? In M. Budja (ed.), Documenta Praehistorica 28: 63-73. 
MABRAY J., SKIBO J. M., SCHIFFER M. B., and KVAMME K. 1988. Use of falling-weight tester for assessing ceramic impact strenght. American Antiquity 53 (4): 829-839.

UREM-KOTSOU D., STERN B., HERON C. and KOTSAKIS K. in press Birch Bark tar at Neolithic Makriyalos, Greece. (to be published in Antiquity 2002).

PAPPA M. and BESIOS M. 1999. The Neolithic Settlement at Makriyalos, Northern Greece: Preliminary Report on the 1993-1995 Excavations. Journal of Field Archaeology 26 (2): 177-195.

PERLÈS C. 1992. Systems of Exchange and Organization of Production in Neolithic Greece. Journal of Mediterranean Archaeology 5 (2): 115-164.

2001. The Early Neolithic in Greece. Cambridge University Press, Cambridge.

PLUCIENNIK M. Z. 1997. Historical, geographical and anthropological imaginations: Early ceramics in Southern Italy. In C. G. Cumberpatch and P. W. Blinkhorn (eds.), Not So Much a Pot, More a Way of Life: $37-56$.

RAVEN A. M., VAN BERGEN P. F., STOTT A. W., DUDD S. N. and EVERSHED R. P. 1997. Formation of longchain ketones in archaeological pottery vessels by pyrolysis of acyl lipids. Journal of Analytical and Applied Pyrolysis 40-41: 267-285.

REGERT M., DELACOTTE J. M., MENU M., PETREQIUN P. and ROLANDO C. 1998. Identification of Neolithic Hafting Adhesives from Two Lake Dwelings at Chalain (Jura, France). Ancient Biomolecules 2: 81-96.

RICE P. M. 1987. Pottery Analysis: A Sourcebook. The University of Chicago Press, Chicago.

SCHIFFER M. B. 1990. The Influence of Surface Treatment on Heating Effectiveness of Ceramic Vessels. Journal of Archaeological Science 17: 373-381.

SCHIFFER M. B. and SKIBO J. M.1989. A Provisional Theory of Ceramic Abrasion. American Anthropologist 91: 101-115.

SCHIFFER M. B., SKIBO J. M., BOELKE T. C., NEUPERT M. A. and ARONSON M. 1994. New Perspectives on Experimental Archaeology: Surface Treatments and Thermal Response in the Clay Cooking Pot. American Antiquity 59 (2): 197-217.
SCHIFFER M. 1988. The Effects of Surface Treatment on Permeability and Evaporative Cooling Effectiveness of Pottery. In R. M. Farquhar, R. G. V. Hancock and L. A. Pavish (eds.), Proceedings of the $26^{\text {th }}$ International Archaeometry Symposium: 23-29.

SKIBO J. M. 1992. Pottery Function: A Use Alteration Perspective. Interdisciplinary Contribution to Archaeology. Plenum Press, New York.

SMITH M. Jr. 1988. Function from Whole Vessel Shape: A Method and an Application to Anasazi Black Mesa, Arizona. American Anthropologist 90: 912923.

STEPONAITIS P. 1984. Technological studies of prehistoric pottery from Alabama: Physical properties and vessel function. In S. van der Leew and A. Pritchard (eds.), The Many Dimensions of Pottery: 79127.

STERN B., HERON C., SERPICO M. and BOURRIAU J. 2000. A Comparison of Methods for Establishing Fatty Acid Concentration Gradients Across Potsherds: A Case Study Using Late Bronze Age Canaanite Amphorae. Archaeometry 42 (2): 399-414.

UREM-KOTSOU D., STERN B., HERON C. and KOTSAKIS K. (in press). Birch Bark tar at Neolithic Makriyalos, Greece.

VITELLI K. 1993. Franchthi Neolithic Pottery: Classification and Ceramic Phases 1 and 2. In T. W. Jacobsen (ed.), Excavation at Franchthi Cave, Greece, 8. Indiana University Press, Bloomington and Indianapolis.

1989. Were Pots First Made for Foods? Doubts from Franchthi. World Archaeology 21 (1): 17-29.

1999. "Looking Up" at Early Ceramics in Greece. In J. M. Skibo and G. M. Feinman (eds.), Pottery and People: A Dynamic Interaction: 184-198.

WOODS A. J. 1986. Form, Fabric, and Function: Some Observations on the Cooking Pot in Antiquity. In W. D. Kingery (ed.), Ceramics and Civilization: Technology and Style, Vol. 2: 157-172.

ZHANG CHI 1999. The Mesolithic and Neolithic in China. In M. Budja (ed.), Documenta Prehistorica 26: 1-14. 